\title{
Measuring conservation program best management practice implementation and maintenance at the watershed scale
}

\author{
D.B. Jackson-Smith, M. Halling, E. de la Hoz, J.P. McEvoy, and J.S. Horsburgh
}

\begin{abstract}
There is growing interest in evaluating the impacts at the watershed scale of agricultural best management practices (BMPs) designed to improve water quality. Many approaches to impact assessment require detailed information about actual BMP use by farmers and landowners in a watershed. This paper examines the strengths and weaknesses of using formal USDA Natural Resources Conservation Service records of conservation program participation as an indicator of spatial and temporal patterns of BMP implementation and maintenance. Field interviews with conservation program participants revealed potential limitations with official records regarding (1) documentation of the incidence of successful BMP implementation, (2) the nature of the BMPs that were implemented, (3) accurate measurement of the timing and location of BMP implementations, and (4) information about the long-term use and maintenance of implemented BMPs. The results suggest that official records should be field-verified before being used as indicators of BMP use. The findings also point to a larger need for development of more robust and accurate systems for tracking BMP implementation and maintenance over periods of time.
\end{abstract}

Key words: best management practice (BMP) implementation-maintenance-measurement-official records-watershed

\begin{abstract}
There is growing interest among policymakers, farmers, and researchers in documenting the impacts of conservation practice adoption on environmental outcomes (Helmers et al. 2007; James and Cox 2008; Mausbach and Dedrick 2004; Van Liew et al. 2007). Numerous approaches to measuring the impacts of best management practices (BMPs) on water quality have been used, ranging from controlled experiments on small research plots or individual farm fields, monitoring of paired watersheds, empirical models that derive output coefficients for broad classes of land use, and process models that simulate the dynamics of watershed physical and hydrologic processes (Cherry et al. 2008). National-level estimates of the impacts of conservation programs have also been developed based on estimates of BMP adoption from large-scale representative sample surveys of farmers (Lambert et al. 2007; USDA NRCS 2009a, 2009b).
\end{abstract}

Efforts to quantify the impacts of realworld agricultural BMPs on water quality at the watershed scale can benefit from the availability of accurate information about the current and past conservation behaviors of farmers and landowners. However, methods for gathering data on conservation behaviors and actual BMP use within watersheds vary widely, and strategies to integrate this information with detailed biophysical monitoring data in analytical models are still in their infancy. One recent initiative designed to address this situation is the USDA Conservation Effects Assessment Program (CEAP) that has coordinated the efforts of 14 existing USDA Agricultural Research Service (ARS) watershed research sites and allocated almost $\$ 8$ million between 2004 to 2007 to fund another 13 non-ARS watershedscale research projects to develop innovative approaches for quantifying the links between BMP implementation and water quality improvements (Duriancik et al. 2008).

Many USDA ARS and non-ARS CEAP watershed projects have struggled to locate temporally and spatially accurate informa- tion about producer conservation behaviors. Some initial results from the 14 ARS watersheds were reported in a recent issue of the Journal of Soil and Water Conservation (see Karlen 2008 for an overview). Ten of the 14 projects report using some type of primary or secondary data to measure farmer conservation behaviors within the boundaries of their study watersheds. Several of the projects relied on aerial photographs, satellite imagery, or visual drive-by surveys, but these methods were limited to documenting the subset of BMPs that can be detected using remote sensing methods (e.g., cropping patterns, tillage practices, grassed waterways, and other large structures) and largely ignored the impact of nutrient and livestock waste management, pest management, and grazing management practices.

The most common and comprehensive source of data on BMP use at the watershed scale (used in at least six of the ARS CEAP watersheds and many of the nonARS CEAP projects) involved the use of government conservation program records to develop tabular and spatial databases that describe the types, extent, and (sometimes) locations of agricultural conservation practices (Bryant et al. 2008; Feyereisen et al. 2008; McCarty et al. 2008; Tomer et al. 2008; Steiner et al. 2008; Wilson et al. 2008). In one prominent instance, researchers have constructed a detailed spatial database of conservation BMPs and made it available to researchers over the Internet (Sullivan and Batten 2007).

Similarly, a review of recent research literature suggests that government program participation records have been used frequently by scientists to help estimate the impacts of agricultural BMPs on water quality conditions. Official records have been utilized to compare the impacts of different densities of BMP use on measured water quality parameters at the subwatershed level (Yates et al. 2007) and to compare water quality conditions at the farm and watershed scale between pre- versus post-BMP imple-

Douglas B. Jackson-Smith is an associate professor, and Michael Halling and Ernesto de la Hoz are masters degree candidates at Utah State University, Logan, Utah. Jamie P. McEvoy is a PhD student the University of Arizona, Tuscon, Arizona. Jeffery S. Horsburgh is a research assistant professor at the Utah Water Research Laboratory at Utah State University, Logan, Utah. 
mentation time periods (Brannan et al. 2000; Currens 2002; Gitau et al. 2008). Although standard watershed process models such as SWAT, AnnAGNPS, and GLEAMS have mainly been used to simulate the effects of hypothetical patterns of BMP usage (Arnold et al 1998; Heathman et al. 2008; Thomas et al. 2007), a growing number of researchers have worked to incorporate information about the types and locations of actual BMP behaviors into these process models at both the field and watershed levels and to compare simulated versus measured water quality outcomes associated with these real-world conservation behaviors (Bracmort et al. 2006, Easton et al. 2008; Rao et al. 2009; Veith et al. 2008).

While a valuable resource, there are several potential limitations to using official conservation program records. Initially, researchers have found agency staff hesitant to release details of individual conservation contract files to nonagency personnel, largely because of legal requirements to protect the confidentiality of contract information. While a memorandum of understanding can be employed to protect the personal information or identities of program participants, these can be very time consuming to negotiate and frequently require approval of state- or national-level agency leaders. For example, the contract data that serve as a basis for this paper were made available to the research team only after nearly a year of discussions and high-level signed agreements. More importantly, program records may not be kept in consistent formats or retained for long periods of time, leading to a labor-intensive process to recover systematic and complete information about project activities.

Finally, there has been little systematic or critical examination in the published literature of the accuracy of government program records as a source of information about conservation behaviors within a watershed. For example, most agricultural watershed water quality projects have utilized the established conservation planning, funding mechanisms, support staff, and program implementation procedures developed by the USDA Natural Resource Conservation Service (NRCS) to create contracts with landowners and farmers to implement conservation practices. As people familiar with NRCS projects know well, standardized practice codes provide consistency in technical definitions across projects (USDA NRCS 2009c, 2009d) and facilitate national practice implementation accounting but are usually too broad to distinguish among a diverse manifestation of local conservation behaviors that share a common code. Details regarding locally variable interpretations of similar structural and management BMPs are difficult to extract from standardized files and NRCS reporting databases, in part because these databases were not designed for this purpose.

Additionally, researchers are beginning to recognize that agricultural technology implementation can be a complex process fraught with difficulties and frequently leads to disadoption or failure (Barham et al. 2004; Bracmort et al. 2004; Walton et al. 2008). Formal program records are often limited to data on the number and extent of BMPs included in the original formal conservation contracts and may lack follow-up information about the degree of BMP implementation success achieved by the landowner or farmer or whether or not the practice was continued or maintained beyond the first year or two of the project. Given the typically rapid rate of change in the size and organization of individual farming operations, as well as the impact of land use changes associated with urbanization and development on agricultural lands, it is likely that the nature and extent of BMP utilization may change over time on many properties involved in conservation programs.

Because official program participation records are the most ubiquitous source of data on BMP implementation at the landscape scale, we use intensive field surveys and interviews with program participants to assess the accuracy of using official records as a measure of short- and long-term BMP use in a northern Utah watershed.

\section{Materials and Methods}

Data for this assessment were gathered as part of a larger analysis of the impacts of past conservation behaviors on trends in measured water quality in the Little Bear River watershed of northern Utah, United States. The research reported here focuses on results of our efforts to field-verify official records of conservation program behaviors as part of a larger watershed assessment effort.

History of the Little Bear River Watershed Project. In the late 1980s, the Little Bear River was identified as having significant water quality impairments due to phosphorus-laden runoff from agricultural operations in the watershed. In response, a comprehensive, multiagency water quality project, known as the Little Bear River Watershed Project (LBRWP), was initiated in 1992 to educate local producers and landowners and to promote the use of BMPs throughout the watershed (Allred et al. 1992). The Little Bear River watershed encompasses about $74 \mathrm{~km}^{2}\left(28.6 \mathrm{mi}^{2}\right)$ of agricultural lands, with approximately $70 \%$ devoted to forests and rangelands, $19 \%$ to irrigated cropland, $7.5 \%$ to dryland grain farming, and $4 \%$ to other uses. Agricultural income is dominated by dairy and beef operations, many of which have extensive irrigated alfalfa fields. Data from the late 1990 s suggests that there were roughly 50 working dairy farms within the watershed, with an average herd size of 120 milk cows per farm (Hardman and Allred 1999).

Based on an assessment of local farming systems and water quality conditions, the LBRWP targeted four critical types of BMPs: manure and nutrient management, grazing management (both on irrigated pastures and in upland rangelands), streambank stabilization, and protection of riparian buffer areas. Based on a review of funded contracts, conversion from flood to sprinkler irrigation systems was also a program priority. Over \$5 million in USDA Hydrologic Unit Area and US Environmental Protection Agency 319 program funds were used to help costshare the implementation of a wide range of BMPs under the LBRWP. Most BMPs were implemented between 1992 and 1998, although smaller numbers of BMP contracts continued to be signed using various USDA NRCS conservation program funds through 2006 (figure 1). Although several state and federal agencies contributed to this effort, most of the project conservation contracts with producers were developed and maintained in the local NRCS county offices.

Official Records. Initially, our team worked in the local USDA NRCS office to review the official contract files for each of the 90 landowners or farmers who participated in the LBRWP between 1992 to 2006. To address confidentiality concerns, our research team developed a detailed memorandum of understanding designed to protect the personal information and identities of program participants. Although it took nearly a year to be approved by state and national-level NRCS leaders, the memorandum enabled us to access detailed file records with the understanding that we would disguise the identities 


\section{Figure 1}

Number and cumulative percent of contracted best management practices in Little Bear River Watershed Project, by best management practice type and contract year.

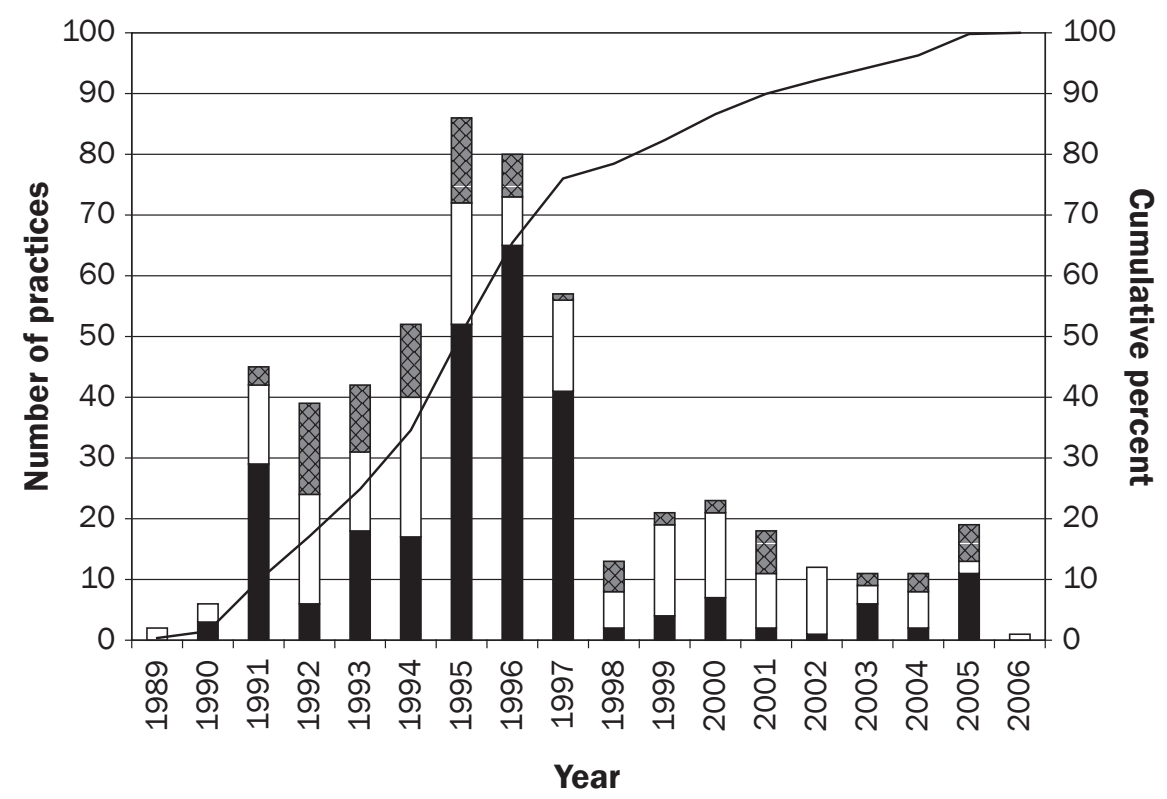

\section{Legend}

Management $\square$ Structure

Planting, clearing, leveling

- Cumulative percent

of the individual participants in the original conservation project.

Over a nine-month period in 2004 to 2005, we gathered and entered into a database (1) official USDA NRCS practice codes (USDA NRCS 2009d) and additional detailed information about each specific conservation practice that participants were contracted to implement during the life of the LBRWP, (2) the USDA Farm Service Agency farm tract and field numbers describing where each practice was located, (3) general information about each operation, and (4) contact information for each program participant. In addition, aerial photographs of each participant's land were photocopied, and based on the information from the files, markings were placed on the photocopied images to signify where each of the contracted BMPs was located on the physical landscape. The markings on the aerial photographs were then digitized to create a geographic information systems database representing individual practices as points, lines, or polygons and linking these spatial representations to the detailed database of BMP locations and characteristics.
Field Interviews. To test the validity and reliability of the LBRWP contract file data and to collect more detailed information about BMP adoption experiences, we conducted extensive personal interviews in 2006 and 2007 with LBRWP participants. In order to set up the interviews, we successively mailed advance letters to eligible project participants on our list. The letter introduced our research team, explained the objectives of our research, and explained that we would be calling them later in the week to set up an interview if they were willing to participate in our research. We then made phone calls to these households to seek their agreement to participate in our study and to arrange an interview time. Because a total of just 90 landowners participated in the conservation program, our team sought to conduct interviews with the complete population list of program participants. Of the original 90 participants, we were able to successfully contact 70 of the participants, and 55 of these agreed to be interviewed for a response rate of $61 \%$ of all LBRWP participants (or 79\% of the participants that we were able to contact). Of the participants that we were unable to contact, 11 did not have current contact information and could not be located, 5 were determined to be deceased, and 4 did not reply to our letters or return our calls. Of those we contacted but did not complete interviews, 11 refused to participate and 4 were unable to finish complete interviews for various reasons. While we are confident that we were able to interview the vast majority of contract recipients still living in the area, it is possible that nonresponse patterns introduced some unknown biases into our reported results.

Most interviews were conducted face to face in the participant's home, and some involved a short tour of the property where conservation practices had been implemented. The length of interviews ranged from 30 to 210 minutes, with most interviews lasting roughly 90 minutes. All interviews were conducted with at least two researchers present, which enabled a more natural interaction and also ensured cross validation of interview notes during post-interview coding. The semistructured interview protocol included standardized open-ended questions about participant household and farm operation characteristics, details on the implementation and current status of each of the conservation practices listed in the USDA NRCS files, and other information about their interactions with LBRWP and NRCS staff. A copy of the survey instrument is available on request from the authors. Although we relied on respondents to recall decisions and behaviors that might have taken place 3 to 15 years earlier, we used copies of materials from their original NRCS project files (including descriptions of contracted BMPs, aerial photographs, and other information) as prompts during the interviews to help jog respondents' memories.

Best Management Practice Validation. A critical part of our project was to validate the information in the USDA NRCS project files. Our goal was to assemble a detailed and highly accurate database of actual conservation behavior in the watershed that identified the locations and dates of BMP installation or adoption, as well as information about any BMP disadoption or discontinuance. Following each interview, we updated the original database of LBRWP BMPs to note instances where the participant reported information that conflicted with that obtained from the NRCS files. Specifically, we noted whether or not the participant recalled implementing the original BMP at all (imple- 
mentation), whether the BMP was accurately characterized by the NRCS practice type coding system (description), whether the type and location of each BMP was correctly represented on our spatial maps (location), and whether or not the BMP still existed or was actively being used (maintenance).

We determined the implementation status for each BMP included in a participant's original files using several techniques. Initially, we shared a list of file BMPs and the aerial photographs with respondents and systematically reviewed each practice to discover whether or not the practice was successfully implemented, whether they encountered any problems during the implementation of the practice, and whether or not they were still using the practice. While a seemingly simple exercise, we quickly discovered that coding the implementation status for BMPs could be complex. During our interviews, we encountered several instances where a respondent indicated no recollection of a particular BMP being part of their contract and numerous others where they insisted that the description of the practice (usually drawn from the NRCS practice code definitions [USDA NRCS 2009d]) was not a completely accurate characterization of what happened. In these instances, we enquired further to ensure that we were not misunderstanding either the file record or the respondent's experiences. Determination of BMP implementation status was most straightforward for practices that involved purchase or construction of physical structures and for those that involved planting, clearing of streams, or land leveling, in large part because these BMPs involved very tangible objects or short-duration activities. On the other hand, adoption of BMPs involving long-term changes in farm management behaviors (such as nutrient management, irrigation water management, grazing management, or pasture and hayland management) was often more ambiguous. In these cases, we repeatedly probed respondents to see if they recalled making any meaningful changes in the relevant categories of management approach and behaviors. If they did change their behavior in any way, we coded the management practice as having been implemented.

During our discussions about BMP implementation, we frequently received information that clarified or changed the ways that we characterized the BMPs and/ or the way that we represented the spatial location and extent of each BMP on our physical maps. In a few cases, we determined that a different USDA NRCS practice code more accurately described the actual practice adopted by the respondent. In many more cases, we developed our own more nuanced practice codes that subdivided NRCS practices into analytically useful subsets. In a few instances, we decided that long lists of repetitive practices were better represented by a single combined code that captured the totality of the practice. The most common example of this was when we combined repeated listings of irrigation pipeline and sprinkler BMPs into a single hybrid code for "irrigation system."

Determination of the maintenance status of each BMP was more straightforward than for implementation. In the case of structural BMPs, we asked whether each BMP was still there and whether or not they were still being used in the manner originally intended. For plantings, land leveling, and stream clearing, we asked if they had been successful and whether they were still present. For management practices, we asked if they still follow the guidelines or behaviors implied by the original BMP.

The net result of our post-interview coding was to create a new set of tabular and spatial databases that represent an updated (and presumably more accurate) catalogue of conservation behaviors in the Little Bear River watershed. In the section that follows, we focus on comparisons between the file view and this new interview view of conservation behaviors associated with the LBRWP, and we reflect on the implications for future research based on using only file view data as inputs into watershed models.

\section{Results and Discussion}

Types of Contracted Best Management Practices. Each BMP in the original LBRWP contract files was coded using the official USDA NRCS "practice code" and description associated with each practice (USDA NRCS 2009c). These three-digit NRCS practice codes are part of a national system that ensures consistent definitions for a wide range of conservation practices that might be employed in different settings. A list of the number of practices included in project files and our interviews is shown in table 1. Based on these descriptions and our fieldwork observations, we classified each BMP code into one of three type categories: structures (34\% of total contracted practices); management practices (49\%); and planting, clearing, and leveling practices (16\%). Figure 1 illustrates the number of different types of BMPs included in contracts between 1989 and 2006. It is clear that most contracted BMPs were initiated during the core project years (1991 to 1997), though the proportion of structural, management, and other BMP types varied by year. Due to our confidentiality agreement with NRCS, we were not allowed to record any financial information from any of the project files. However, we were able to use project publications, public records of the annual meetings of the local Conservation Districts where contracts were approved, and staff recollections to determine which individual practices were eligible for cost-sharing during different phases of the LBRWP. Overall, we estimate that roughly $75 \%$ of contracted BMPs were eligible and likely to have received cost-sharing.

Our fieldwork was able to ascertain the implementation and maintenance status of a representative majority of project-funded BMPs. The files for the 90 project participants included references to 58 different USDA NRCS practice codes and a total of 848 distinct BMPs or an average of 9.4 practices per contract. Our research team was able to gather field-validation information for 554 total practices, or $65.3 \%$ of all contracted project BMPs, and our interviews were able to obtain information on the status of the majority of contracted practices for 50 of the 58 BMP practice code types.

Characterizing Best Management Practices. As noted above, interviews frequently identified information that suggested that we make modifications or additions to the USDA NRCS codes attached to specific practices. Of the 554 practices covered during our interviews, roughly one third were adjusted in some manner to better allow us to characterize them in our database. One prominent example is the NRCS code for fencing (582). Given that we were interested in practices that might affect water quality outcomes, we discovered that the generic fencing BMP code was insufficiently detailed to distinguish between streambank fences, field enclosure fences, and interior cross-fences within pastures, each of which would potentially have very different effects on water quality. Of the 53 instances of fencing BMPs, we reclassified 29 as streambank fences, 21 as internal pasture cross fences, 
Table 1

Complete list of conservation practices in Little Bear River Watershed Project contract files, by best management practice (BMP) type.

\begin{tabular}{|c|c|c|c|c|c|c|c|c|}
\hline $\begin{array}{l}\text { Practice } \\
\text { cluster }\end{array}$ & $\begin{array}{l}\text { Practice } \\
\text { code }\end{array}$ & $\begin{array}{l}\text { BMP } \\
\text { type* }\end{array}$ & $\begin{array}{l}\text { Cost } \\
\text { sharing }\end{array}$ & Practice name & $\begin{array}{l}\text { Total BMPs } \\
\text { in files }\end{array}$ & $\begin{array}{l}\text { Percent of } \\
\text { BMPs in files }\end{array}$ & $\begin{array}{l}\text { Total BMPs } \\
\text { in interviews }\end{array}$ & $\begin{array}{l}\text { Percent } \\
\text { interviewed }\end{array}$ \\
\hline \multicolumn{9}{|c|}{ Crop production practices } \\
\hline & 324 & M & None & Chiseling and subsoiling (deep tillage) & 1 & & 1 & 100.0 \\
\hline & 327 & PCL & All & Conservation cover & 14 & & 12 & 85.7 \\
\hline & 328 & $\mathrm{M}$ & Few & Conservation crop rotation & 25 & & 16 & 64.0 \\
\hline & 329 & M & Few & Residue and tillage mgt (aka cons tillage) & 12 & & 9 & 75.0 \\
\hline & 344 & M & All & Residue management & 1 & & 1 & 100.0 \\
\hline & 586 & M & None & Stripcropping & 1 & & 1 & 100.0 \\
\hline & 590 & M & Few & Nutrient management & 10 & & 8 & 80.0 \\
\hline & 595 & M & Few & Pest management & 16 & & 12 & 75.0 \\
\hline & & & & Subtotal & 80 & 9.4 & 60 & 75.0 \\
\hline \multicolumn{9}{|l|}{ Irrigation } \\
\hline & 362 & $\mathrm{~S}$ & All & Water diversion & 4 & & 4 & 100.0 \\
\hline & 430 & $\mathrm{~S}$ & All & Irrigation water conveyance pipe & 33 & & 18 & 54.5 \\
\hline & 436 & $\mathrm{~S}$ & All & Irrigation storage reservoir & 1 & & 1 & 100.0 \\
\hline & 442 & $\mathrm{~S}$ & All & Irrigation system, sprinkler & 5 & & 3 & 60.0 \\
\hline & 443 & $\mathrm{~S}$ & All & Irrigation systems, surface and subsurface & 1 & & 1 & 100.0 \\
\hline & 449 & M & Most & Irrigation water mgmt. & 53 & & 28 & 52.8 \\
\hline & 464 & PCL & All & Irrigation land leveling & 9 & & 5 & 55.6 \\
\hline & 533 & $\mathrm{~S}$ & All & Pumping plant & 2 & & 1 & 50.0 \\
\hline & 587 & $\mathrm{~S}$ & All & Structure for water control & 10 & & 7 & 70.0 \\
\hline & 665 & M & None & Operation and maintenance & 1 & & 1 & 100.0 \\
\hline & $9400 \dagger$ & $\mathrm{S}$ & All & Sprinkler system & 21 & & 14 & 66.7 \\
\hline & & & & Subtotal & 140 & 16.5 & 83 & 59.3 \\
\hline Pasture/ & razing ma & lageme & & & & & & \\
\hline & 314 & M & Most & Brush management & 16 & & 11 & 68.8 \\
\hline & 338 & M & None & Prescribed burning & 3 & & 1 & 33.3 \\
\hline & 352 & M & Half & Deferred grazing & 18 & & 14 & 77.8 \\
\hline & 378 & $\mathrm{~S}$ & All & Pond & 8 & & 6 & 75.0 \\
\hline & 510 & M & Most & Pasture and hayland management & 55 & & 36 & 65.5 \\
\hline & 512 & PCL & All & Pasture and hay planting & 33 & & 18 & 54.5 \\
\hline & 521 & $\mathrm{~S}$ & All & Pond sealing or lining & 3 & & 3 & 100.0 \\
\hline & 528 & M & Few & Prescribed grazing & 44 & & 32 & 72.7 \\
\hline & 550 & PCL & All & Range planting & 27 & & 24 & 88.9 \\
\hline & 556 & $\mathrm{M}$ & Most & Planned grazing system & 25 & & 18 & 72.0 \\
\hline & 574 & $\mathrm{~S}$ & All & Spring development & 20 & & 15 & 75.0 \\
\hline & 614 & $\mathrm{~S}$ & All & Watering facility (trough) & 16 & & 11 & 68.8 \\
\hline & 645 & M & Few & Upland wildlife habitat management & 57 & & 38 & 66.7 \\
\hline & & & & $\begin{array}{r}\text { Subtotal } \\
\end{array}$ & 325 & 38.3 & 227 & 69.8 \\
\hline Waste $\mathbf{m}$ & nagement & & & & & & & \\
\hline & 312 & M & None & Waste management systems & 13 & & 12 & 92.3 \\
\hline & 313 & $\mathrm{~S}$ & All & Waste storage facility & 25 & & 22 & 88.0 \\
\hline & 425 & $\mathrm{~S}$ & All & Waste pond & 1 & & 1 & 100.0 \\
\hline & 633 & M & Most & Waste utilization & 21 & & 11 & 52.4 \\
\hline & 634 & $\mathrm{~S}$ & All & Waste transfer pipe & 2 & & 1 & 50.0 \\
\hline & & & & Subtotal & 62 & 7.3 & 47 & 75.8 \\
\hline Fencing & & & & & & & & \\
\hline & 382 & S & All & Fence & 91 & & 53 & 58.2 \\
\hline & & & & Subtotal & 91 & 10.7 & 53 & 58.2 \\
\hline
\end{tabular}


Table 1 (Continued)

Complete list of conservation practices in LBRWP contract files, by best management practice (BMP) type.

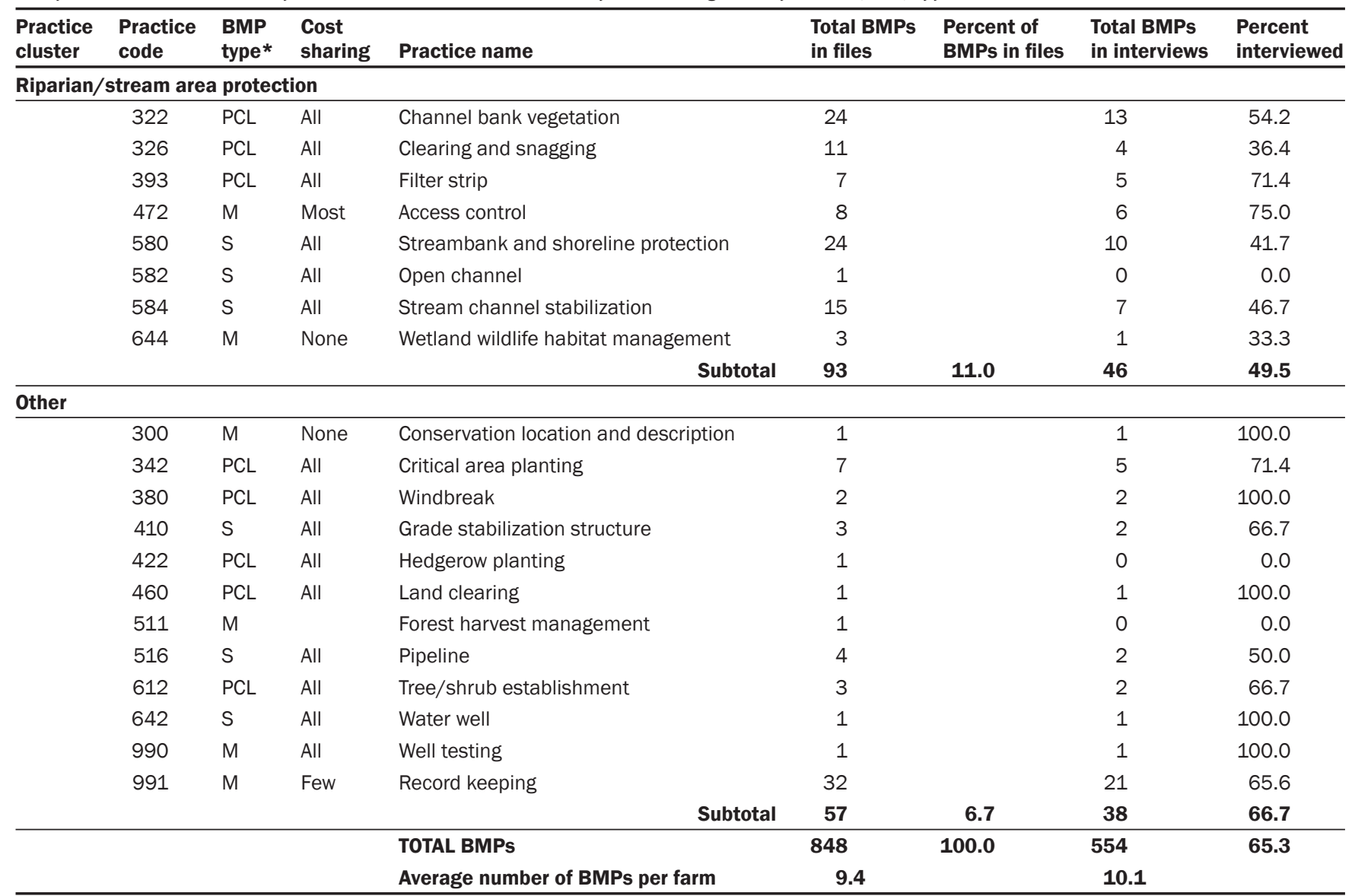

* BMP type codes: $\mathrm{M}=$ management practice. $\mathrm{PCL}=$ planting, clearing or leveling. $\mathrm{S}=$ structure.

† $9400=$ consolidated category that includes multiple replications of pipeline and sprinkler BMPs on single field.

2 as perimeter pasture fences, and 1 as a fence around a pond. The location of many of these fences on farm maps was also frequently corrected by respondent feedback during the interviews. In addition to making the fencing data more detailed and accurate, field interviews also "discovered" another 13 instances of fencing activity with potential water quality impacts that had been carried out by project participants during the same time frame but which were not officially sponsored by the LBRWP.

Another BMP category whose characterization benefited from fieldwork was USDA NRCS 313 (waste storage facilities). Of the 22 instances of 313 codes discussed in the interviews, we were able to clarify for all farms what types of wastes were meant to be held in each facility (liquids, solids, or both). We also discovered 7 instances where there were actually multiple storage structures (many of which were not correctly located on the file maps). In addition, we found instances where the project involved construction of structures that were not traditional manure storage facilities, including several cases where the 313 code referenced the construction of cement corrals or animal holding areas, from which manure presumably could more readily be collected than the previous dirt-floored facilities. In two instances, the code referenced the construction of linear cement walls against which manure could be pushed to aid in its collection. Finally, our field interviews identified three instances of manure storage facilities that had been originally classified using a different NRCS code (425-waste pond, 362water diversion, and 587-structure for water control). While each of these may be technically valid examples of 313 practices, their relative impacts on manure storage capability and/or water quality protection are likely to be quite different.
The interviews also identified numerous instances where the spatial location and extent of coverage of BMPs needed to be clarified. Specifically, the spatial representation of implemented BMPs in our geographic information system database was updated for roughly $16 \%$ of the practices included in the interviews. The vast majority of the spatial adjustments involved changing the boundaries of fields and areas that were impacted by a management BMP (usually reducing the likely footprint of these practices). Other common changes involved clarifying the location of structural BMPs. In addition to clarifying spatial information for implemented BMPs, we were also able to include information in our spatial database about practices that were not fully implemented or that were discontinued at some point (as discussed later). Finally, the interviews identified 59 new conservation practices (not part of the LBRWP) that we were able to add to 
our revised map of conservation behaviors in the watershed.

Best Management Practice Implementation.

The primary motivation for conducting field interviews with project participants was to verify that all contract BMPs were actually implemented and were still being maintained. Table 2 reports the number and percent of contracted BMPs in various stages of implementation. Overall, we determined that project participants could not verify implementation for 88 (16\%) of the contracted BMPs. Most of these were instances where all available evidence pointed to a failure to successfully implement the practice, though a handful of cases involved misclassified BMPs where a different type of practice was actually carried out. In almost every case of nonimplemented BMPs, respondents simply did not recognize the practice as being part of their original project. Another group described what they had done in connection to a contracted management BMP, but it was apparent to the research team that their actions did not meet even a minimal definition of the changes in behavior implied by adoption of this type of BMP. For example, they might recall having had a nutrient management BMP in their contract, but their nutrient management decisions and behaviors were essentially unchanged by participation in the LBRWP. Only a very small handful of respondents recognized that a BMP was in their contract but volunteered that they actively decided not to implement the practice.

Table 2 also shows that instances of BMP nonimplementation were relatively common across all of the farms included in the interviews. In more than two-thirds of the interviews, at least one BMP was reported as not implemented. This suggests that the overall patterns of nonimplementation cannot be explained by the presence of a few poorly implemented contracts. Meanwhile, only one farm reported the failure to implement any of their contracted practices.

We believe that these are reasonably conservative estimates of practice implementation during the life of the LBRWP. While we believe that a failure of respondent recall could explain some of these apparently nonimplemented practices, we also recognize that there is an innate bias in favor of respondents to report implementation, even if it did not occur. Moreover, our analysis was relatively generous in classifying some types of man-

Table 2

Apparent implementation status of best management practices (BMPs).

\begin{tabular}{lrr}
\hline Implementation status of file BMPs & Number & Percent \\
\hline Practice-level analysis & & \\
\hline No evidence file BMP was implemented & 79 & 14.6 \\
Other BMP implemented (misclassified BMP in file) & 9 & 1.7 \\
$\quad$ Subtotal: file BMP not implemented & $\mathbf{8 8}$ & $\mathbf{1 6 . 3}$ \\
File BMP partially implemented & 20 & 3.7 \\
File BMP fully implemented & 429 & 79.3 \\
$\quad$ Subtotal: file BMP implemented & $\mathbf{4 4 9}$ & $\mathbf{8 3 . 0}$ \\
Unable to determine & 4 & 0.7 \\
\hline Total & $\mathbf{5 4 1}$ & $\mathbf{1 0 0 . 0}$ \\
\hline Farm-level analysis & & 31.5 \\
\hline Farm implemented all file BMPs* & 17 & 59.3 \\
Farm implemented $\geq 50 \%$ file BMPs & 32 & 7.4 \\
Farm implemented < 50\% file BMPs & 4 & 1.9 \\
Farm implemented none of file BMPs & 1 & $\mathbf{1 0 0 . 0}$ \\
\hline Total & $\mathbf{5 4}$ &
\end{tabular}

* Only includes practices in the partial and full implementation categories.

Table 3

Current status of best management practices (BMPs) from Little Bear River Watershed Project.

\begin{tabular}{lccc}
\hline Current status of BMP & Number & $\begin{array}{l}\text { Percent of } \\
\text { implemented } \\
\text { BMPs* }\end{array}$ & $\begin{array}{c}\text { Percent } \\
\text { of all file } \\
\text { BMPs }\end{array}$ \\
\hline Never done originally $\dagger$ & 88 & na & 16.3 \\
Not there anymore (structures or plantings) & 20 & 4.4 & 3.7 \\
No longer done (management) & 63 & 13.9 & 11.6 \\
There but not used (structures) & 11 & 2.4 & 2.0 \\
$\quad$ Subtotal of not maintained & $\mathbf{9 4}$ & $\mathbf{2 0 . 8}$ & $\mathbf{1 7 . 4}$ \\
Still there with original purpose-being used as intended & 339 & 74.8 & 62.7 \\
Can't determine & 20 & 4.4 & 3.7 \\
\hline Total & $\mathbf{5 4 1}$ & $\mathbf{1 0 0 . 0}$ & $\mathbf{1 0 0 . 0}$ \\
\hline Note: na = not applicable. & & & \\
* Only includes practices in the partial and full implementation categories. & \\
† Combines first two categories from table 2. & & &
\end{tabular}

agement practices as "implemented," despite the relatively modest changes in management behavior reported by project respondents.

Best Management Practice Maintenance. Once we identified the BMPs that had been implemented, we gathered detailed information about the current status (or ongoing maintenance and use) of these practices. There are few published studies of the longterm maintenance of conservation BMPs in the literature, and these have focused only on structural practices whose operational functionality could be visually assessed by experts using remote sensing and field inspections of BMPs (Bracmort et al. 2004; Lindsey et al. 1992). In our case, we relied on detailed conversations with project participants, often complemented with visual surveys of prac- tices during tours of their farms. Overall, we determined that over $20 \%$ of implemented BMPs appeared to be no longer maintained or in use (table 3). Most of the nonmaintained practices involved management BMPs that were no longer used by the respondent. There were also 20 instances of structural or planting BMPs that were no longer in existence and another 11 that were present but were not being used. The net result of nonimplementation and nonmaintenance suggests that two-thirds of all of the conservation practices contracted under the LBRWP between 1989 to 2006 were still being actively utilized in 2007.

There are several reasons an implemented BMP might no longer be used. In our analysis, we divided these reasons into two main 
clusters: respondents who were still engaged in farming but who had stopped using the practice and respondents who were no longer farming in a manner that would make use of the BMP appropriate (table 4). The former group represented two-thirds of all respondents and includes people for whom use of the BMP would theoretically still make sense, as well as a number of respondents who indicated that they had the impression that their BMP was temporary or was not intended to be used for more than a few years (e.g., spraying for weeds). The latter group accounts for roughly a third of all nonmaintained BMPs and reflects the impact of changes that made BMPs irrelevant to their current operation, including decisions to stop using BMPs because their farm had downsized or shed livestock enterprises and those who had seen their lands converted to nonfarm development.

Patterns of Implementation and Maintenance. As a final stage of our analysis, we compared the rate of implementation and maintenance of different types of BMPs. The results are shown in table 5. Specifically, we discovered that the rate of implementation gradually increased across the lifespan of the project. This seems to suggest that project staff learned over time how to write more accurate and effective contracts. When we clustered BMPs by farming enterprise, it appears that BMPs related to crop production enterprises and irrigation systems had the lowest implementation rate $(74 \%$ to $75 \%)$, followed by pasture and grazing planting and management BMPs (81\%). By contrast, nearly every instance of fencing and riparian protection structures in the files were found to have been implemented on the study farms. Generally speaking, structural BMPs and practices for which cost-sharing was available were more likely to be implemented, perhaps because they involved greater investment of public and private funds. However, the implementation gap between cost-shared and noncost-shared practices was not as significant as we anticipated when we began the study. Although cost-sharing is often believed to be an essential incentive to encourage use of BMPs, in this study, a majority of unfunded practices appear to have been implemented, though the rate of implementation was significantly lower.

Maintenance of the implemented BMPs also varies across time, though the pattern was less clear than for implementation. For exam-
Table 4

Explanation for nonmaintenance of best management practices (BMPs).

\begin{tabular}{llc}
\hline Reasons for why BMP is no longer used & $\begin{array}{l}\text { Number of } \\
\text { nonmmaintained } \\
\text { BMPs }\end{array}$ & $\begin{array}{l}\text { Percent of } \\
\text { nonmaintained } \\
\text { BMPs }\end{array}$ \\
\hline Still farming, but not using & & 25.5 \\
\hline Discontinued management practice & 24 & 11.7 \\
Structure abandoned or removed & 11 & 8.5 \\
Plants died off & 8 & 22.3 \\
Temporary practice (not intended to continue) & 21 & $\mathbf{6 8 . 1}$ \\
$\quad$ Subtotal & $\mathbf{6 4}$ & 16.0 \\
\hline No longer farming & & 16.0 \\
\hline Downsized or discontinued farming & 15 & $\mathbf{3 1 . 9}$ \\
Land sold off for development $\quad 15$ & $\mathbf{1 0 0 . 0}$ \\
$\quad$ Subtotal & $\mathbf{3 0}$ & \\
\hline Total & $\mathbf{9 4}$ & \\
& &
\end{tabular}

\section{Table 5}

Implementation and maintenance patterns by best management practices (BMP) characteristics.

\begin{tabular}{|c|c|c|c|}
\hline BMP characteristic & $\begin{array}{l}\text { Percent } \\
\text { implemented }\end{array}$ & $\begin{array}{l}\text { Percent } \\
\text { maintained* }\end{array}$ & $\begin{array}{l}\text { Percent } \\
\text { original BMPs } \\
\text { still there }\end{array}$ \\
\hline \multicolumn{4}{|l|}{ By contract year } \\
\hline 1989 to 1991 & 63.5 & 69.7 & 44.2 \\
\hline 1992 to 1995 & 86.2 & 78.0 & 68.1 \\
\hline 1996 to 1998 & 80.7 & 73.3 & 59.3 \\
\hline 1999 to 2001 & 91.9 & 98.2 & 91.9 \\
\hline 2002 to 2006 & 92.6 & 74.0 & 70.4 \\
\hline Chi-squared test $p$-value & 0.000 & 0.002 & 0.000 \\
\hline \multicolumn{4}{|l|}{ By farming enterprise } \\
\hline Crop production practices & 75.0 & 82.1 & 59.3 \\
\hline Irrigation equipment and management & 74.4 & 83.6 & 64.6 \\
\hline Pasture/grazing planting and management & 80.9 & 76.0 & 62.8 \\
\hline Fencing & 100.0 & 90.2 & 90.2 \\
\hline Livestock waste structures and management & 88.6 & 77.4 & 68.6 \\
\hline Riparian/stream area protection structures & 97.8 & 80.0 & 78.3 \\
\hline Other BMPs & 88.9 & 54.8 & 48.6 \\
\hline Chi-squared test $p$-value & 0.000 & 0.012 & 0.000 \\
\hline \multicolumn{4}{|l|}{ By BMP type } \\
\hline Structural & 95.6 & 85.5 & 82.8 \\
\hline Planting, clearing and leveling & 89.8 & 91.1 & 83.0 \\
\hline Management & 73.3 & 65.9 & 48.6 \\
\hline Chi-squared test $p$-value & 0.000 & 0.000 & 0.000 \\
\hline \multicolumn{4}{|l|}{ By cost-sharing status } \\
\hline Cost-shared & 86.5 & 80.8 & 71.3 \\
\hline Not cost-shared & 77.8 & 70.1 & 53.5 \\
\hline Chi-squared test $p$-value & 0.020 & 0.035 & 0.000 \\
\hline Total & 83.6 & 78.1 & 66.2 \\
\hline
\end{tabular}

* Percent of those BMPs that were originally implemented. 
ple, the BMPs included in contracts signed between 1999 and 2001 were most likely to be still maintained, while those signed since 2002 were no more likely to still be present than practices involved in contracts from the early and mid-1990s. A closer analysis of the most recent contract period suggests that implemented but nonmaintained practices involved one-time treatments of land for weeds or pests, contracts with farms that quit farming or dispersed their livestock herds, and structures that broke and were not repaired. Again, structural practices were more likely than management practices to be maintained, though practices that involved planting, clearing, and land leveling had the lowest rates of fallout once they had been successfully implemented. Not surprisingly, practices that were eligible to receive cost sharing were more likely to be maintained.

Combining information about implementation and maintenance, the last column of table 5 reports the percent of originally contracted BMPs on study farms that are still being actively used. Overall, roughly twothirds of all BMPs in the project files were still being used on the farms that we interviewed. Conversely, one-third of LBRWP practices are no longer actively influencing water quality outcomes. Practices that were contracted more recently were somewhat more likely to be maintained, though there is not a simple linear pattern associated with age of contract. Practices involving fencing, riparian area protection, and livestock waste management were more likely to be maintained than practices targeting crop production, irrigation, and pasture and grazing management. While over $80 \%$ of structural and planting BMPs were still in the field, less than one-half of the management BMPs were still actively being used by project respondents. Finally, almost half of the BMPs that were not eligible for cost-sharing were no longer being used, compared to $30 \%$ of cost-shared BMPs.

\section{Summary and Conclusions}

Our findings suggest that official watershed program contracts and related records can be a very useful resource for describing patterns of conservation behaviors at the watershed scale but that they may not provide a complete and accurate description of BMP adoption and related behaviors instigated by a conservation program. In particular, the characterization of BMPs typically recorded in USDA NRCS files may be too vague to allow reliable estimates of their impact on watershed processes and water quality impacts. The actual location and spatial extent of landscapes or areas impacted by specific BMPs is likely to be somewhat overstated, particularly for management practices. Program records may generate false positive indicators of the presence of BMPs, since a significant subset of contracted BMPs may not have been fully implemented and another subset will likely have been discontinued or not maintained during the life of the project. Finally, there are likely to be false negatives related to unmeasured additional conservation practices that were adopted by program participants (and most likely, program nonparticipants) over the same time period.

Patterns of contracted BMP implementation and maintenance suggest some important lessons for the assessment of conservation program impacts. Our results imply that management practices are particularly susceptible to nonimplementation and maintenance. Yet management behaviors are increasingly recognized as critical to the success of conservation programs. Installation of structures without the adoption of associated management behaviors may produce little net benefit to watershed goals. The use of cost-sharing does improve the rate of implementation and maintenance but to a smaller degree than we originally expected. In this watershed, practices targeted at crop production practices and irrigation systems had lower implementation rates than some of the practices aimed at livestock systems and riparian area protection.

Researchers seeking to explain variability in water quality parameters measured at the subwatershed and watershed scales often require the use of detailed information about actual adoption of structural and management BMPs. Typically these researchers would rely on program records to describe patterns of BMP implementation. Our results suggest that detailed watershed modeling might benefit from supplemental fieldwork with all or a sample of project participants to increase the accuracy of information about the types and locations of BMPs in a watershed. Our fieldwork uncovered many instances of BMP nonimplementation and nonmaintenance, as well as instances of noncontracted conservation behaviors that took place on participating farms. We were also able to clarify the description and location of a significant proportion of contracted BMPs, including recoding practices into important subtypes likely to have markedly different impacts on water quality outcomes.

Our results also suggest that more followup contacts with project participants could be useful for conservation program design and adaptive management strategies. Patterns of nonimplementation can be used to adjust lists of eligible BMPs and to adjust estimates of expected conservation benefits from different types of practices. Patterns of nonmaintenance can help target practices that are appropriate for intensive follow-up monitoring. Additionally, a significant proportion of nonmaintained BMPs were "undone" by farm enterprise downsizing and conversion to nonfarm housing. This suggests that consideration of the future plans for the farming operation and evaluation of the likelihood of conversion of agricultural lands might be included when ranking proposals for conservation contracts. Although not discussed at length here, our fieldwork also provided critical feedback on the barriers to BMP implementation and maintenance encountered by typical project participants. This feedback can be used to adjust procedures used to identify appropriate BMPs, to provide better targeted assistance for some types of BMP implementation, and to engage project participants in more long-term monitoring efforts.

In the experience of our research team members and in our discussions with people working on watershed projects across many different regions of the United States, it would appear that agricultural watershed project staff traditionally invest most of their time and resources into encouraging eligible landowners to participate in their programs, providing technical and financial assistance to approved contractees, and reporting basic information about the number and extent of contracted BMPs to state and federal agencies. Our results suggest that there are many potential benefits to developing better tracking systems for post-contract implementation and long-term maintenance of BMPs. The USDA NRCS has official policies and procedures in place to review contract implementation (under 440 CPM 512.55), although evaluations appear to focus on cost-shared structural practices, address short-term implementation (and not longterm maintenance), and emphasize technical issues related to cost-share rates, accounting 
for in-kind contributions and whether or not the affected land is still managed by the contract recipient. Expanding periodic field visits to randomly sampled participants in public conservation programs, particularly 5 to 10 years after initial implementation, can yield important feedback that can shape the design of future conservation efforts.

We conclude with a final word of caution regarding the interpretation of our findings. While we have classified BMPs into discrete "implemented" and "not implemented" categories, we are painfully aware that our classifications are affected by recall errors by project participants and by possible misinterpretations of the original file information by our research team. We did not conduct systematic interviews of the original LBRWP staff, and their recollections of individual farm contracts might have helped increase the accuracy of our classifications. Finally, we do not wish to suggest that the instances of BMP "nonimplementation" or "nonmaintenance" uncovered in our study reflect examples of deliberate malfeasance, subterfuge, or even illegality. Almost all failures to implement or maintain practices involved good faith efforts by program staff and program participants to follow through on the terms of the original conservation contracts.

\section{Acknowledgements}

We particularly thank the landowners who agreed to participate in our project for taking the time to share their experiences with our team. We also thank USDA NRCS staff for their generous assistance and willingness to facilitate our data collection during the various stages of this project. Without their support, this analysis would not have been possible. This research was supported by the USDA Cooperative State Research, Education, and Extension Service CEAP Competitive Watershed Grant UTAW-2004-05671.

\section{References}

Allred, M., G. Jorgenson, and R. Clark. 1992. Utah Little Bear River Hydrologic Unit Plan.

Arnold, J.G., R. Srinivasan, R.S. Muttiah, and J.R. Williams. 1998. Large area hydrologic modeling and assessmentPart 1: Model development. Journal of the American Water Resources Association 34(1):73-89.

Barham, B.L., J.D. Foltz, D. Jackson-Smith, and S. Moon. 2004. The dynamics of agricultural biotechnology adoption: Lessons from rBST use in Wisconsin 19942001. American Journal of Agricultural Economics 86(1):61-72
Bracmort, K.S., M.Arabi,J.R. Frankenberger, B.A. Engel, and J.G. Arnold. 2006. Modeling long-term water quality impact of structural BMPs. Transactions of the American Society of Agricultural and Biological Engineers 49(2):367-374.

Bracmort, K.S., B.A. Engel, and J.R. Frankenberger. 2004 Evaluation of structural best management practices 20 years after installation: Black Creek watershed, Indiana. Journal of Soil and Water Conservation 59(5):191-196.

Brannan, K.M., S. Mostaghimi, P.W. McClellan, and S. Imamdar. 2000. Animal waste BMP impacts on sediment and nutrient losses in runoff from the Owl Run watershed. Transactions of the American Society of Agricultural and Biological Engineers 43(5):1155-1166. Bryant, R.B., T.L. Veith, P.J.A. Kleinman, and W.J. Gburek. 2008. Cannonsville Reservoir and Town Brook watersheds: Documenting conservation efforts to protect New York City's drinking water. Journal of Soil and Water Conservation 63(6):339-344, doi:10.2489/jswc.63.6.339.

Cherry, K.A., M. Shepherd, P.J.A. Withers, and S.J. Mooney. 2008. Assessing the effectiveness of actions to mitigate nutrient loss from agriculture: A review of methods. Science of the Total Environment 406:1-23.

Currens, J.C. 2002. Changes in groundwater quality in a conduit-flow-dominated karst aquifer, following BMP implementation. Environmental Geology 42:525-531.

Duriancik, L.F., D. Bucks, J.P. Dobrowolski, T. Drewes, S.D. Eckles, L. Jolley, R.L. Kellogg, D. Lund, J.R. Makuch, M.P. O’Neill, C.A. Rewa, M.R. Walbridge, R. Parry, and M.A. Weltz. 2008. The first five years of the Conservation Effects Assessment Project. Journal of Soil and Water Conservation 63(6):185A-197A doi:10.2489/jswc.63.6.185A.

Easton, Z.M., M.T. Walter, and T.S. Steenhuis. 2008. Combined monitoring and modeling indicate most effective agricultural best management practices. Journal of Environmental Quality 37:1798-1809.

Feyereisen, G.W., R. Lowrance, T.C. Strickland, D.D. Bosch, and J.M. Sheridan. 2008. Long-term stream chemistry trends in the southern Georgia Little River Experimental Watershed. Journal of Soil and Water Conservation 63(6):475-486, doi:10.2489/jswc.63.6.475.

Gitau, M.W., W.J. Gburek, and P.L. Bishop. 2008. Use of the SWAT model to quantify water quality effects of agricultural BMPs at the farm-scale level. Transactions of the American Society of Agricultural and Biological Engineers 51(6):1925-1936.

Hardman, J., and M. Allred. 1999. Little Bear River Hydrologic Unit Area: Overview. Project Factsheet. Obtained from USDA/NRCS Cache County, Utah Office, April 2008.

Heathman, G.C., D.C. Flanagan, M. Larose, and B.W Zuercher. 2008. Application of the Soil and Water Assessment Tool and Annualized Agricultural NonPoint Source models in the St. Joseph River watershed.
Journal of Soil and Water Conservation 63(6):552-568, doi:10.2489/jswc.63.6.552.

Helmers, M.J., T.M. Isenhart, C.L. King, T.B. Moorman, W.W. Simpkins, and M. Tomer. 2007. Agriculture and water quality in the cornbelt: Overview of issues and approaches. Choices 22(2). http:// www.choicesmagazine.org/2007-2/waterquality/ 2007-2-01.htm.

James, P., and C.A. Cox. 2008. Building blocks to effectively assessing the environmental benefits of conservation practices. Journal of Soil and Water Conservation 63(6):178A-180A, doi:10.2489/jswc.63.6.178A.

Karlen, D.L. 2008. A new paradigm for natural resources research: The Conservation Effects Assessment Project. Journal of Soil and Water Conservation 63(6):220A, doi:10.2489/jswc.63.6.220A.

Lambert, D., G.D. Schaible, R. Johansson, and U. Vasavada. 2007. The value of integrated CEAP-ARMS survey data in conservation program analysis. Journal of Soil and Water Conservation 62(1):1-10.

Lindsey, G., L. Roberts, and W. Page. 1992. Maintenance of stormwater BMPs in four Maryland counties: A status report. Journal of Soil and Water Conservation 47(5):417-422.

Mausbach, M.J., and A.R. Dedrick. 2004. The length we go: Measuring environmental benefits of conservation practices. Journal of Soil and Water Conservation 59(5):96A-103A.

McCarty, G.W., L.L. McConnell, C.J. Hapeman, A. Sadeghi, C. Graff, W.D. Hively, M.W. Lang, T.R. Fisher, T. Jordan, C.P. Rice, E.E. Codling, D. Whitall, A. Lynn, J. Keppler, and M.L. Fogel. 2008. Water quality and conservation practice effects in the Choptank River watershed. Journal of Soil and Water Conservation 63(6):461-474, doi:10.2489/jswc.63.6.461.

Rao,V.S., Z.M. Easton, E.M. Schneiderman, M.S. Zion, D.R Lee, and T.S. Steenhuis. 2009. Modeling watershed-scale effectiveness of agricultural best management practices to reduce phosphorus loading. Journal of Environmental Management 90:1385-1395.

Steiner, J.L., P.J. Starks, J.A. Daniel, J.D. Garbrecht, D. Moriasi, S. McIntyre, and J.-S. Chen. 2008. Environmental effects of agricultural conservation: A framework for research in two watersheds in Oklahoma's Upper Washita River Basin. Journal of Soil and Water Conservation 63(6):443452, doi:10.2489/jswc.63.6.443.

Sullivan, D.G., and H.L. Batten. 2007. Little River Experimental Watershed, Tifton, Georgia, United States: A historical geographic database of conservation practice implementation. Water Resources Research 48: W09471, doi:10.1029/2006WR005836.

Thomas, M.A., B.A. Engel, M. Arabi, T. Zhai, R. Farnsworth, and J.R. Frankenberger. 2007. Evaluation of nutrient management plans using an integrated modeling approach. Applied Engineering in Agriculture 23(6):747-755 
Tomer, M.D., T.B. Moorman, D.E. James, G. Hadish, and C.G. Rossi. 2008. Assessment of the Iowa River's South Fork watershed: Part 2. Conservation practices. Journal of Soil and Water Conservation 63(6):371-379, doi:10.2489/jswc.63.6.371.

USDA NRCS (Natural Resources Conservation Service). 2009a. CEAP National Assessment. Washington DC: USDA Natural Resources Conservation Service. http:// www.nrcs.usda.gov/Technical/nri/ceap/assessment.html. USDA NRCS. 2009b. CEAP Farmer Surveys. Washington DC: USDA Natural Resources Conservation Service. http:// www.nrcs.usda.gov/technical/nri/ceap/surveys.html.

USDA NRCS. 2009c. National Conservation Practice Standards, National Handbook of Conservation Practices. Washington DC: USDA National Natural Resources Conservation Service. http://www.nrcs.usda. gov/technical/standards/nhcp.html.

USDA NRCS. 2009d. Electronic Field Office Technical Guide, Cache County, Utah. Salt Lake City, UT: Utah NRCS State Office. http://efotg.nrcs.usda.gov/ treemenuFS.aspx.

Van Liew, M.W., T.L. Veith, D.D. Bosch, and J.G. Arnold. 2007. Suitability of SWAT for the conservation effects assessment project: Comparison of USDA agricultural research service watersheds. Journal of Hydrologic Engineering 12(2):173-189.

Veith, T.L., A.N. Sharpley, and J.G. Arnold. 2008. Modeling a small, northeastern watershed with detailed, fieldlevel data. Transactions of the American Society of Agricultural and Biological Engineers 51(2):471-483.

Walton, J.C., D.M. Lambert, R.K. Roberts, J.A. Larson, B.C. English, S.L. Larking, S.W. Martin, M.C. Marra, K.W. Paxton, and J.M. Reeves. 2008. Adoption and abandonment of precision soil sampling in cotton production. Journal of Agricultural and Resource Economics 33(3):428-448.

Wilson, G.V., F.D. Shields, Jr., R.L. Bingner, P. Reid-Rhoades, D.A. DiCarlo, and S.M. Dabney. 2008. Conservation practices and gully erosion contributions in the Topashaw Canal watershed. Journal of Soil and Water Conservation 63(6):420-429, doi:10.2489/jswc.63.6.420.

Yates,A.G., R.C.Bailey, and J.A.Schwindt. 2007. Effectiveness of best management practices in improving stream ecosystem quality. Hydrobiologia 582:331-344. 